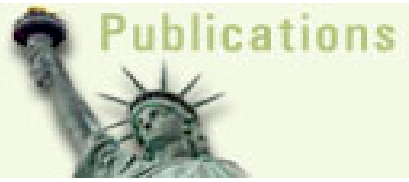

American Journal of Applied Sciences 5 (1): 1-6, 2007

ISSN 1546-9239

(C) 2007 Science Publications

\title{
Influence of Fasteners Disposition on Behaviour of Timber-Framed Walls with Double Fibre-Plaster Coating Boards
}

\author{
M.Kuhta and M.Premrov \\ University of Maribor, Faculty of Civil Engineering, Smetanova 17 \\ SI - 2000 Maribor, Slovenia
}

\begin{abstract}
This paper provides experimental analysis of timber-framed walls, coated with double fibreplaster coating boards fastened to the timber frame. As the walls under a horizontal load actually behave like a deep composite beam, the fasteners disposition is very important and directly influences bearing capacity and stiffness of the wall. Therefore, three different groups of test samples with staple distances of $\mathrm{s}=37.5,75$ and $150 \mathrm{~mm}$ were experimentally analysed and compared. For groups $\mathrm{G} 2$ and G3 the failure of FPB occurred. It has been shown that proposed simplified Eurocode 5 methods, applicable for wood-based sheathing board might be unsuitable for the problems presented.
\end{abstract}

Keywords: structures, walls, fibre-plaster boards, fasteners; experiments

\section{INTRODUCTION}

There is an increasing tendency worldwide to build multi-level prefabricated timber structures with timberframed walls as the main bearing capacity elements. Treated walls consist of solid timber frame coated by sheets of board-material fixed by mechanical fasteners to one or both sides of the timber frame (Fig. 1). There are many types of panel sheet products available which may have some structural capacity such as wood-based materials (plywood, oriented strand board, hardboard, particleboard,) or plaster and fibre-plaster boards (FPB), made from gypsum, recently the most frequently used in Central Europe. In this research we will limit our attention to FPB only. It may be useful to underline that the precise type of fibrous panel product used in the walls tested in this research is not common in North America, though presented results may be of interest to engineers attempting to develop techniques for the reinforcement of wood-framed walls sheathed with essentially brittle panel products. One of the most important reasons for an increased application of these types of gypsum products is namely their relatively good fire protection. For example, single gypsum sheathed board of $15 \mathrm{~mm}$ thickness assures 45 minutes of fire protection. Additionally, gypsum is a healthy natural material and is consequently particularly desired for residential buildings. On the other hand, from a structural point of view its tensile strength is very low, approximately 10-times lower than the compressive strength, and can not be compared with the overall strength of the timber frame. Because the treated walls are loaded by a horizontal force at the top of the wall they actually behave like deep composite elements, where FPB is usually the weaker part. Thus, especially in multi-level buildings located in seismic or windy areas, cracks in FPB regularly usually appear.

There are several possibilities to reinforce the walls in order to avoid cracks in FPB. In Dobrila and Premrov ${ }^{[6]}$ experimental results using additional FPB were presented. The test samples with constant distance of $\mathrm{s}=75 \mathrm{~mm}$ between the staples demonstrated higher elasticity, whilst bearing capacity and especially ductility were not improved in the desired range. In the second solution, using diagonal steel strips ${ }^{[6]}$, it is evident from the relationship between the measured forces forming the first crack that the inserted steel diagonals are not very important. But the proportion between the measured crushing forces shows that the resistance of the reinforced panel's increases by $77 \%$ and ductility is improved by $39 \%$. It is important that the diagonals are fixed to the timber frame. In this case only a part of the horizontal force is shifted from boards over the tensile steel diagonal to the timber frame after appearance of the first crack in the tensile zone of FPB. In the third solution, using CFRP strips, which are glued in the tensile diagonal direction to the FPB, is the strengthening concept such that the composites would contribute to tensile capacity when the tensile strength of FPB is exceeded. As shown, there is practically no

Corresponding Author: $\quad$ M. Premrov, University of Maribor, Faculty of Civil Engineering, Smetanova 17; SI - 2000 Maribor, Slovenia,Tel: + 38622294 303, Fax: + 38622524279 
influence on the element stiffness of any reinforcement before cracks appeared in the un-strengthened FPB. However, after the first cracks in un-strengthened FPB appeared, the test samples demonstrated an important difference in behaviour dependant on the boundary conditions between the inserted CFRP strips and the timber frame ${ }^{[3]}$.

\section{MATERIALS AND METHODS}

Design Methods: In structural analysis panel walls for design purposes can be regarded separately as vertical cantilever beams with the horizontal force $\left(\mathrm{F}_{\mathrm{H}}=\mathrm{F}_{\mathrm{H}, \mathrm{tot}} / \mathrm{n}\right)$ acting at the top, see Fig. 1. Considered supports approximate an influence of neighbouring panel walls and assure an elastic-clamped boundary condition for
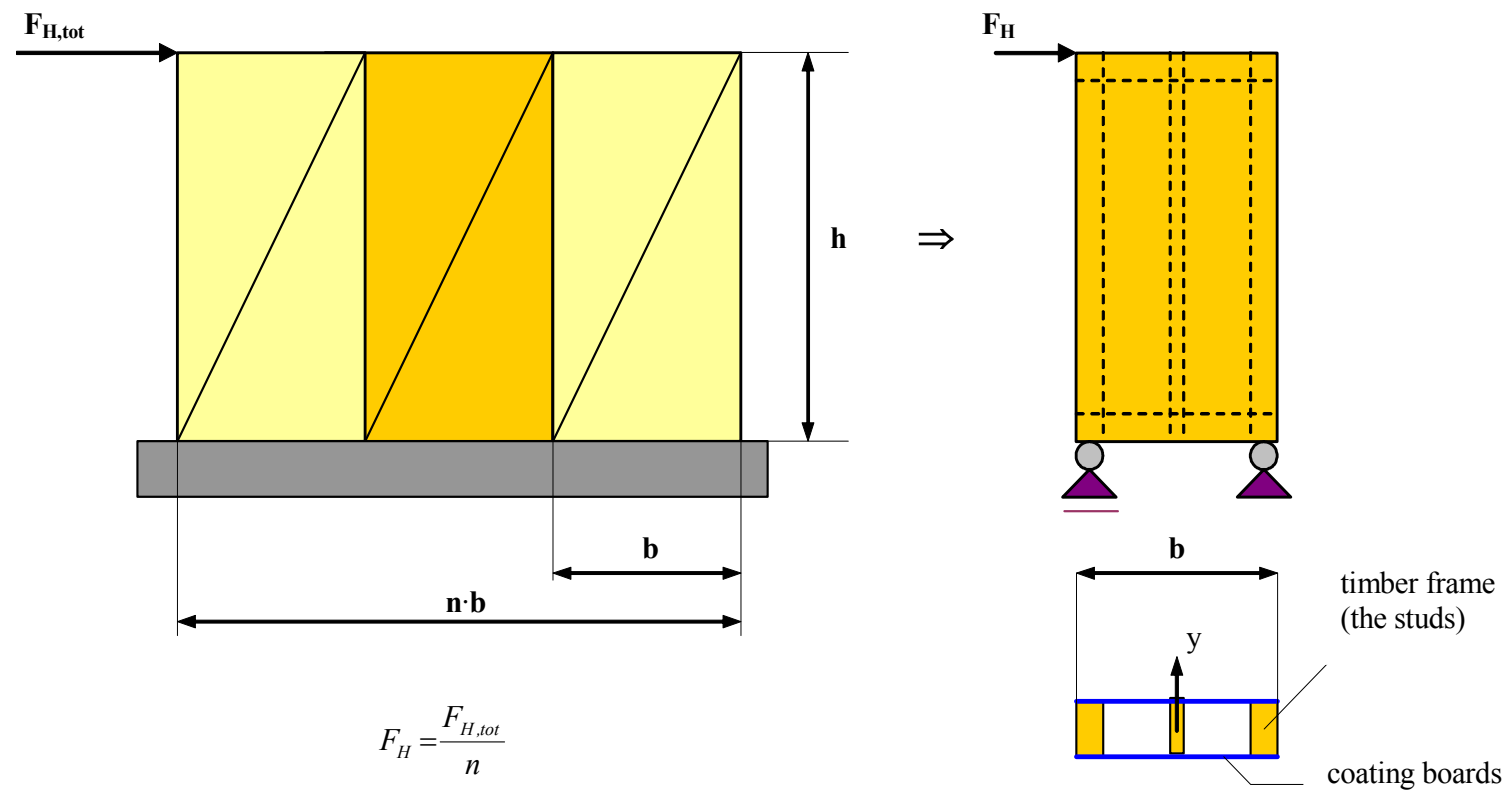

Fig. 1: Static design and cross section of the treated panel wall

the treated wall, as can be found for example in Faherty and Williamson ${ }^{[1]}$, Hoyle and Woeste ${ }^{[5]}$ and Eurocode $5^{[4]}$.

Shear Models: Many design models have been proposed in order to analyse and predict the behaviour of wood-based shear walls and diaphragms subjected to lateral loads. Källsner ${ }^{[7]}$ and Äkerlund ${ }^{[8]}$ proposed an approach to determine the load-carrying capacity of the wall unit, based on the following key assumptions: a.) behaviour of the joints between the sheet and the frame members is assumed to be linear-elastic until failure, b.) the frame members and the sheets are assumed to be rigid and hinged to each other. The influence of shear deformations in the fibreboard can be additionally estimated introducing the shear angle. Additionally, two models are presented based on the assumption that the load-displacement relation of fasteners is completely plastic. Källsner and $\mathrm{Lam}^{[9]}$ presented the walls loadcarrying capacity as a function of fasteners spacing along the upper horizontal timber member assuming constant fastener spacing along all timber members. Two simplified computational methods are given in Eurocode $5^{[4]}$ in order to determine the load-carrying capacity of the wall diaphragm. The first simplified analysis - Method A, is identical to the «Lower bound plastic method «, presented by Källsner and Lam ${ }^{[9]}$. This method defines the wall's shear resistance $\left(\mathrm{F}_{\mathrm{v}, \mathrm{d}}\right)$ as a sum of all the fasteners' lateral resistances along the loaded edges:

$$
F_{v, d}=\sum F_{f, R d} \cdot \frac{b_{i}}{s} \cdot c_{i} ; \quad c_{i}=\left\{\begin{array}{ll}
1 & \text { for } b_{i} \geq b_{0} \\
\frac{b_{i}}{b_{0}} & \text { for } b_{i} \leq b_{0}
\end{array} ; \mathrm{b}_{0}=\mathrm{h} / 2\right.
$$

where $F_{f, R d}$ is lateral design capacity per fastener, $b_{i}$ is a wall panel width Fig. 1 and $\mathrm{s}$ is fastener spacing in the connecting plane between the timber frame and the coating boards. This is only an approximated and simplified definition, which can be applicable for wood-based panels where the strength is relatively high 
and the elements tend to fail because of fastener yielding.

The second simplified analysis - Method B is applicable to walls made from sheets of wood-based panel products only, fastened to a timber frame. The fastening of the sheets to the timber frame should either be by nails or screws, and the fasteners should be equally spaced around the perimeter of the sheet. According to Method A the sheathing material factor $\left(\mathrm{k}_{\mathrm{n}}\right)$, the fastener spacing factor $\left(\mathrm{k}_{\mathrm{s}}\right)$, the vertical load factor $\left(\mathrm{k}_{\mathrm{i}, \mathrm{q}}\right)$ and the dimension factors for the panel $\left(\mathrm{k}_{\mathrm{d}}\right)$ are included in the design procedure in the form of:

$F_{v, d}=\sum F_{f, R d} \cdot \frac{b_{i}}{s_{0}} \cdot c_{i} \cdot k_{d} \cdot k_{i, q} \cdot k_{s} \cdot k_{n} ; \quad s_{0}=\frac{9700 \cdot d}{\rho_{k}}$

where $\mathrm{d}$ is the fastener diameter and $\rho_{\mathrm{k}}$ is characteristic density of the timber frame.

Composite Models: All the above mentioned methods are usually unsuitable for treated walls sheathed with fibre-plaster boards (FPB). The main assumptions do not exactly coincide with the real state of FPB, in which the tensile strength is evidently lower than the compressive strength. Consequently, cracks in a tensile zone usually appear under heavy horizontal loads before stresses on the fasteners reach their yielding point, and the fibreboards usually do not behave as rigid elements ${ }^{[6]}$. However, using FPB as a coating material, a horizontal load shifts a part of the force over the mechanical fasteners to the fibreboard and the wall acts like a deep beam ${ }^{[1]}$. Distribution of the horizontal force by composite treatment of the element depends on the proportion of stiffness. The effective bending stiffness $\left(E I_{y}\right)_{\text {eff }}$ of mechanically jointed beams considering the flexibility of fasteners via coefficient $\gamma_{y}$, using s.c." $\gamma$ method", taken from Eurocode ${ }^{[4]}$, can be written in the form of:

$$
\begin{aligned}
& \left(E I_{y}\right)_{\text {eff }}=\sum_{i=1}^{n} E_{i} \cdot\left(I_{y i}+\gamma_{y i} \cdot A_{i} \cdot a_{i}^{2}\right)= \\
& \sum_{i=1}^{n_{\text {timber. }} .}\left(E_{i} \cdot I_{y i}+E_{i} \cdot \gamma_{y i} \cdot A_{i} \cdot a_{i}^{2}\right)_{\text {timber }}+\sum_{j=1}^{n_{\text {board }}}\left(E_{i} \cdot I_{y i}\right)_{\text {board }}
\end{aligned}
$$

where $\mathrm{n}$ is the total number of elements in the considered cross-section and $a_{i}$ is a distance between global $\mathrm{y}$-axis of the whole cross-section and local $\mathrm{y}_{\mathrm{i}}$ axis of the $i$-th element with a cross-section $A_{i}$, see Fig. 2. It is evident that the force distribution in this case strongly depends on the stiffness coefficient of the connecting area $\left(\gamma_{\mathrm{y}}\right)$, which mostly depends on the fasteners slip modulus $\left(\mathrm{K}_{\mathrm{ser}}\right)$ and fasteners disposition, as well as on the type of the connection. Approximate semi-analytical models which enable simultaneous consideration of the fasteners' flexibility between the boards and the timber frame, any appearing cracks in the tensile area of the FPB, as well as the steel diagonals' influence in a case of diagonal strengthening of the boards, are in details developed and described in Premrov, M., Dobrila, P., Bedenik, B.S. ${ }^{[2]}$ and will not be presented here.

\section{RESULTS AND DISCUSSION}

Experimental Analysis: In the following analysis we will limit our attention to the walls with double fibreplaster coating boards, the first strengthening method given in Section 2, which is in industry the most popular way to avoid cracks in FPB. However, as it is mentioned in Section 2.2, the wall's behaviour strongly depends on the shear stiffness in the connecting area. Therefore, our intention was to investigate the influence of fastener disposition with three different distances between the fasteners.

Test configuration: Three sample groups from total of nine test samples were tested in order to carry out appropriate experimental research on the influence of fasteners' disposition. All test groups (G1, G2 and G3) consisted of three panel walls having actual dimensions of $\mathrm{h}=264 \mathrm{~cm}$ and $\mathrm{b}=125 \mathrm{~cm}$. The cross-section presented in Fig. 2 was composed of timber studs $(2 \times 9 \times 9 \mathrm{~cm}$ and $1 \times 4.4 \times 9 \mathrm{~cm})$, timber girders $(2 \times 8 \times 9 \mathrm{~cm})$ and doubled Knauf fibre-plaster boards ${ }^{[10]}$ of single thickness $\mathrm{t}=15 \mathrm{~mm}$. They were fixed together to the timber frame, as shown on Fig. 2, using staples of $\Phi 1.53 \mathrm{~mm}$ at a constant spacing of $\mathrm{s}=37.5 \mathrm{~mm}(\mathrm{G} 1), \mathrm{s}$ $=75.0 \mathrm{~mm}(\mathrm{G} 2)$ and $\mathrm{s}=15.0 \mathrm{~mm}(\mathrm{G} 3)$.

The static model according to Fig. 1 was used for all groups of test samples. The samples were actually rotated by $90^{\circ}$ according to Fig. 1 and they were therefore subjected to vertical force acting at the end of the elements, see Fig. 3. To prevent lateral torsion buckling on free side of the element the vertical roller support was introduced. 


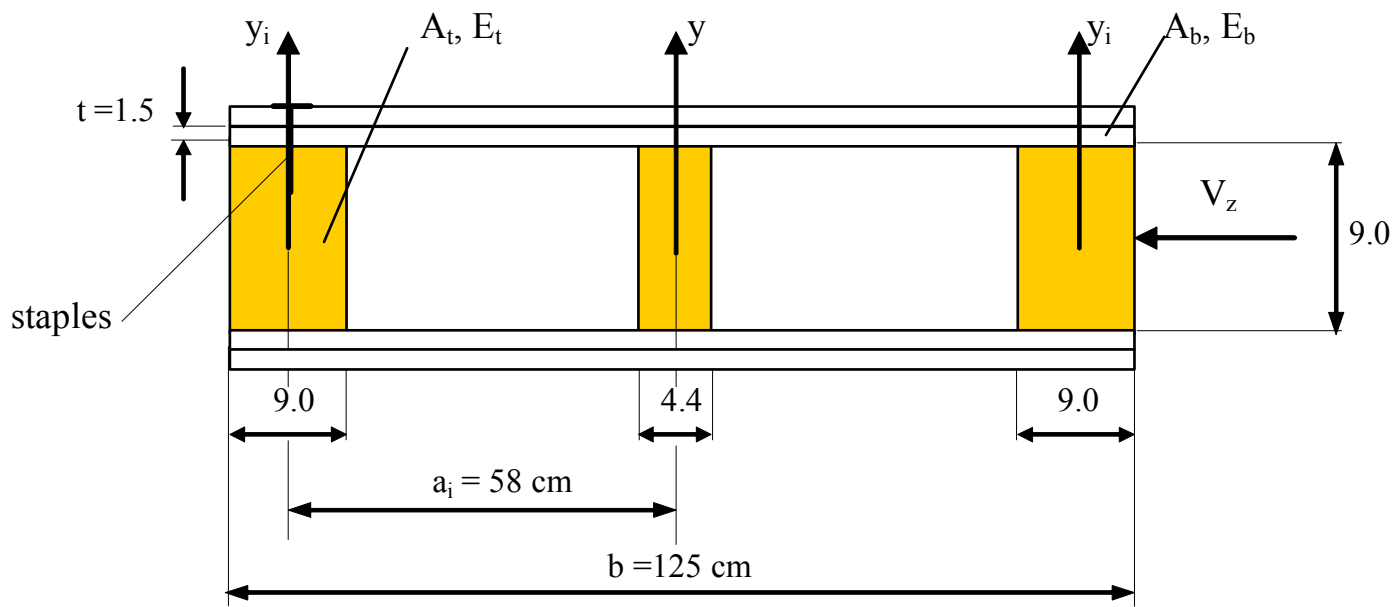

Fig. 2: Cross-section of the test samples

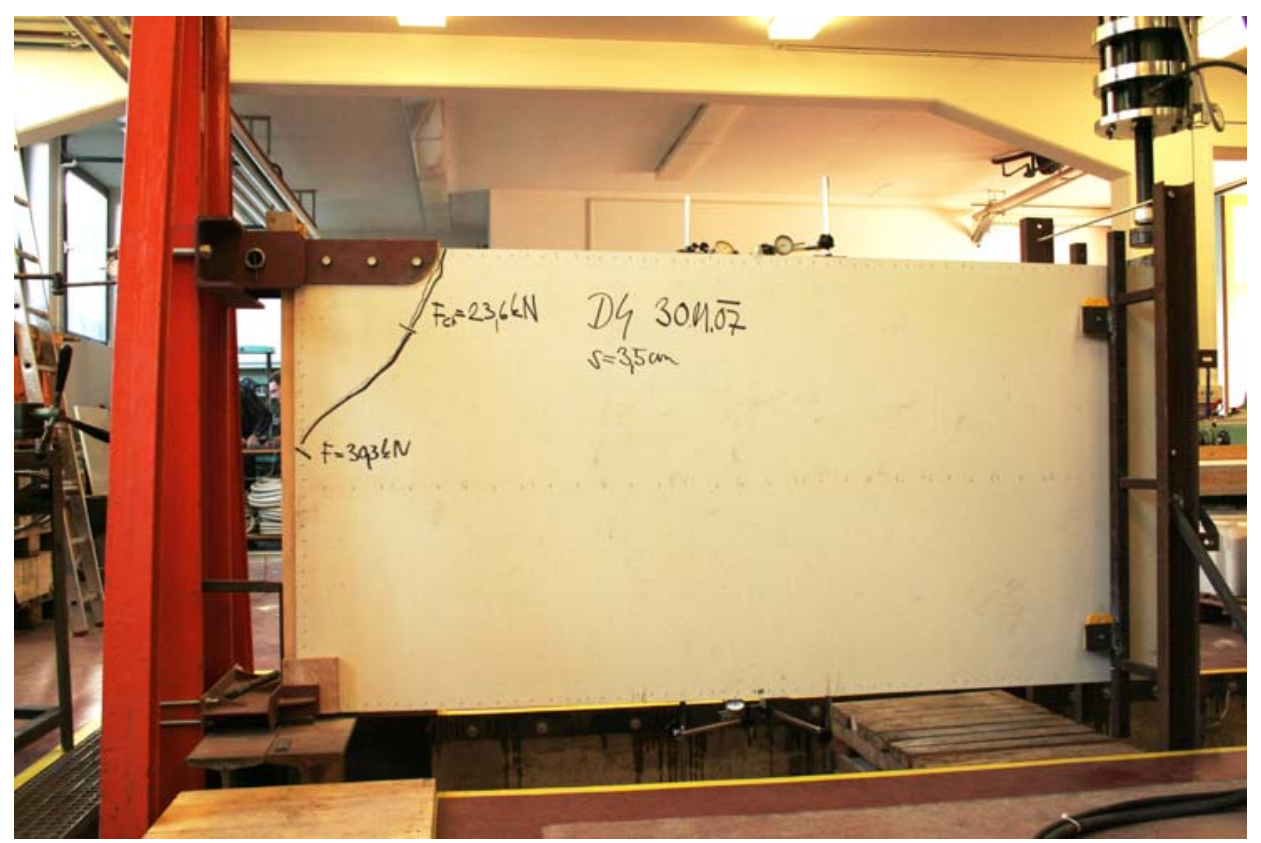

Fig. 3: Static system of the test samples

Test samples material properties for all groups were the same and are given in Table 1. Values for solid timber of quality $\mathrm{C} 22$ are taken from $\mathrm{EN} 338^{[11]}$ and the characteristics of fibre-plaster boards from Knauf ${ }^{[10]}$.

Test results: The force forming first crack $\left(\mathrm{F}_{\mathrm{cr}}\right)$ in the FPB, the crushing force $\left(F_{u}\right)$, the maximal cantilever bending deflection $(\mathrm{w})$ under the acting force $(\mathrm{F})$ and the slip $(\Delta)$ in the tensile and compressive zone between the FPB and the timber frame were measured. The measured values for the G1 test samples were taken from Premrov, M., Dobrila, P., Bedenik, B.S. ${ }^{[6]}$ and additional new test samples from this research.

Average force forming the first crack $\left(\mathrm{F}_{\mathrm{cr}}\right)$ :

G1: $\quad F_{\text {cr, } 1}=25.35 \mathrm{kN} \quad$ G2: $\quad F_{\text {cr }, 2}=22.84 \mathrm{kN}$

G3: $\quad \mathrm{F}_{\mathrm{cr}, 3}=20.07 \mathrm{kN}$

Average crushing force $\left(\mathrm{F}_{\mathrm{u}}\right)$ :

G1: $\quad F_{u, 1}=37.29 \mathrm{kN} \quad$ G2: $\quad F_{u, 2}=32.17 \mathrm{kN}$

G3: $\quad F_{u, 3}=20.87 \mathrm{kN}$ 
Table 1: Properties of applied materials

\begin{tabular}{lccccccc}
\hline & $\mathrm{E}_{0, \mathrm{~m}}$ & $\mathrm{G}_{\mathrm{m}}$ & $\mathrm{f}_{\mathrm{m}, \mathrm{k}}$ & $\mathrm{f}_{\mathrm{t}, 0, \mathrm{k}}$ & $\mathrm{f}_{\mathrm{c}, 0, \mathrm{k}}$ & $\mathrm{f}_{\mathrm{v}, \mathrm{k}}$ & $\rho_{\mathrm{m}}$ \\
& {$\left[\mathrm{N} / \mathrm{mm}^{2}\right]$} & {$\left[\mathrm{N} / \mathrm{mm}^{2}\right]$} & {$\left[\mathrm{N} / \mathrm{mm}^{2}\right]$} & {$\left[\mathrm{N} / \mathrm{mm}^{2}\right]$} & {$\left[\mathrm{N} / \mathrm{mm}^{2}\right]$} & {$\left[\mathrm{N} / \mathrm{mm}^{2}\right]$} & {$\left[\mathrm{kg} / \mathrm{m}^{3}\right]$} \\
Timber C22 & 10000 & 630 & 22 & 13 & 20 & 2.4 & 410 \\
FPB & 3000 & 1200 & 4.0 & 2.5 & 20 & 5.0 & 1050 \\
\hline
\end{tabular}

Forces $\left(\mathrm{F}_{\mathrm{cr}}\right)$ and $\left(\mathrm{F}_{\mathrm{u}}\right)$ depend on fasteners disposition. It is evident that the stiffness of the connecting shear plane $\left(\gamma_{\mathrm{y}}\right)$ increased with lower staples spacing according to composite behaviour. Consequently the stresses are higher in timber frame, lower in FPB and the cracks are forming at higher forces as for samples G2 and G3. By further increase of loading higher than $\mathrm{F}_{\mathrm{cr}}$ the failure of tension girder is evident for group $\mathrm{G} 1$, while for groups G2 and G3 the failure of FPB occurred. To obtain a better understanding of the wall's behaviour, see Fig. 4 presents an average vertical displacements $(\mathrm{w})$ measured at the top of the wall under the acting vertical force $(\mathrm{F})$, as well as average slip in the tensile $\left(\Delta_{\mathrm{t}}\right)$, see Fig. 5.a and compressive $\left(\Delta_{\mathrm{c}}\right)$ timber frame - FPB connecting area Fig. 5.b.

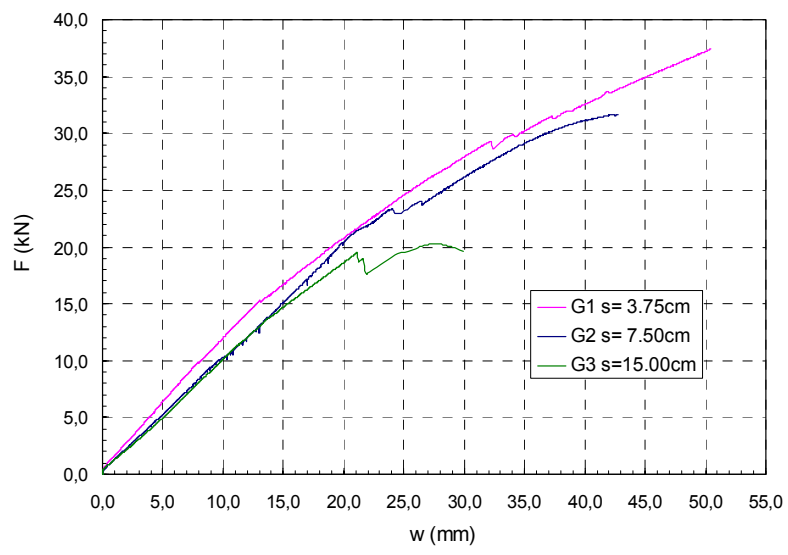

Fig. 4: F-w diagram

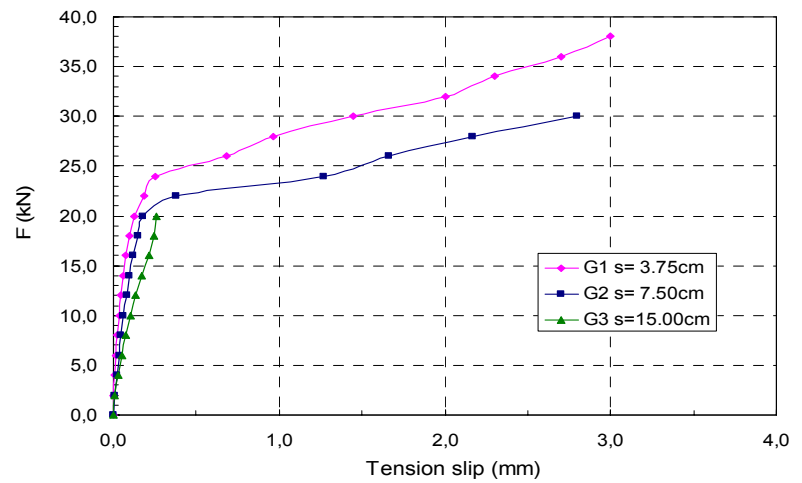

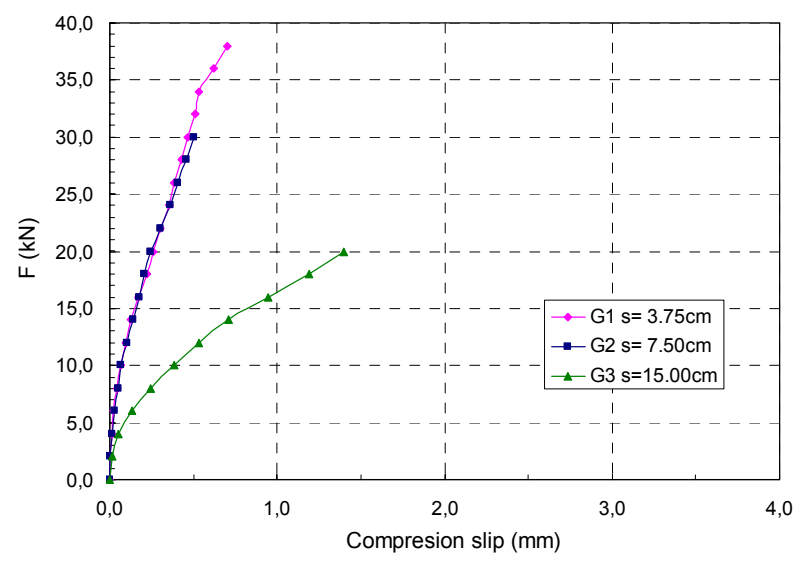

Fig. 5: a) F- $\Delta_{t}$ diagram, b) F- $\Delta_{c}$ diagram

\section{CONCLUSION}

It is evident from F-w diagram Fig. 4 that the bending stiffness of sample G1 is higher than bending stiffness of samples G2 and G3. The difference is due to smaller staples spacing which is represented in higher coefficient $\gamma$ and higher bending stiffness $\left(\mathrm{El}_{\mathrm{y}}\right)_{\text {off }}$ according to Eq. (3).

The appearance of the first crack is noticed from F- $\Delta_{\mathrm{t}}$ diagram Fig. 5.a and it is evident that slip before the first crack in FPB is higher for G3 samples and seems to be logical as the stiffness of the connecting shear plane is lower in this case. The lower slope of G3 samples is noticeable from Fig. 5. The stiffness of the connecting shear plane, as shown in Fig. 5, is approximately the same until the appearance of the first crack in FPB and start to differ with increasing force. The behavior of staples after the first crack occurred in the connecting shear plane of the compressive zone of the element is almost elastic, but in the tension zone plastification occurred.

\section{ACKNOWLEDGEMENTS}

The authors wish to acknowledge the support of company Marles, which provided test samples for this work. 


\section{REFERENCES}

1. Faherty, K.F., T.G. Williamson, 1989. Wood Engineering and Construction Handbook. Mc Graw-Hill Publishing Company.

2. Premrov, M., P.Dobrila, B.S. Bedenik, 2004. Approximate analytical solutions for diagonal reinforced timber-framed walls with fibre-plaster coating material. Constr. build. mater. 18 (10), 727-735.

3. Premrov, M., P.Dobrila, B.S. Bedenik, 2004. Analysis of timber-framed walls coated with CFRP strips strengthened fibre-plaster boards. International Journal of Solids and Structures 41 (24/25), 7035-7048.

4. Eurocode 5: Design of Timber Structures, Part 1-1: General rules and rules for buildings, 2003. European Comitee for Standardization (CEN/TC 250/SC5 N173), Brussels.

5. Hoyle, R.J., F.E. Woeste, 1989. Wood Technology in the Design of Structures. Iowa State University Press, Ames, Iowa.
6. Dobrila, P., M. Premrov, 2003. Reinforcing methods for composite timber frame-fiberboard wall panels. Engineering Structures 25(11), 13691376.

7. Källsner, B.,1984. Panels as wind-bracing elements in timber-framed walls. Swedish Institute for Wood Technology Research, Report 56, Stockholm.

8. Äkerlund, S., 1984. Enkel beräkningsmodell för skivor på regelstomme (Simple calculation model for sheets on a timber frame). Bygg \& Teknik, No.1.

9. Källsner, B., F. Lam, 1995. Diaphragms and shear walls. Holzbauwerke: Grundlagen, Entwicklungen, Ergänzungen nach Eurocode 5, Step 3, Fachverlag Holz, Düsseldorf, pp. 15/1-17.

10. Knauf Gipsfaserplatten Vidivall/Vidifloor 2002.

11. European Committe for Standardization, 2003. EN 338:2003 E: Structural timber - Strength classes. Brussels. 